\title{
Linking FrameNet and Natural Languages via Thematic Role Structures
}

\author{
Yılmaz Kılıçaslan and Gurkan Tuna
}

\begin{abstract}
The aim of this paper is twofold. On the one hand, it is argued that thematic roles can be organized into three hierarchical fields: the locative field, the figural field, and the psychological field. On the other hand, the paper offers insights into how to link FrameNet to these fields. Three frames are proposed to carry out such a linking function: Intentionally_affect, Transitive_action, and Mental_activity. It is suggested that constituents of natural language sentences can be linked to the relevant parts of FrameNet via the mediation of these frames and the thematic fields.
\end{abstract}

Index Terms-FrameNet, frames, semantic roles, thematic roles, thematic fields.

\section{INTRODUCTION}

The relation between natural language and lexical resources /ontologies has been a subject of growing concern in natural language processing, computational linguistics and knowledge engineering in recent years. The aim of this paper is to consider whether thematic roles can be structurally organized as abstract models that can serve as a link between natural language and FrameNet, which is a large-scale lexical resource (database). More specifically, the paper argues that a hierarchically organized structure of thematic roles can function as an interface between not only the lexical but also the structural aspects of language and FrameNet.

\section{FRAMENET}

FrameNet is based on Frame Semantics [1]-[11]. The main idea behind Frame Semantics is that words in human language are never interpreted in isolation but are always understood with respect to frames ${ }^{1}$. Fillmore defines a frame as a schematization of experience which relates the elements and entities with a culturally embedded scene from human experience. In other words, a frame is a description of a situation or entity along with its participants.

Each frame is associated with a name and an informal definition in the FrameNet database. For instance, the frame representing the meaning of $c u t$ is named Cutting and defined as a situation where an Agent cuts an Item into Pieces using an Instrument.

Manuscript received May 15, 2015; revised August 19, 2015.

Y. Kilıçaslan is with the Department of Computer Engineering, Trakya University, Edirne, Turkey (e-mail: yilmazkilicaslan@ trakya.edu.tr).

G. Tuna is with the Department of Computer Programming, Trakya University, Edirne, Turkey (e-mail: gurkantuna@trakya.edu.tr).

${ }^{1}$ A persuasive argument in favor of the view that words cannot exist in one's mind as in a dictionary, but using the term 'domain' instead of 'frame' is presented in [12].
Frames come with a number of core and non-core frame elements which can be thought of as the semantic roles played by the participants. While core frame elements are necessary to the central meaning of the frames, non-core frame elements are those that are not necessary for a unique characterization of the frames [13]. The core frame elements specified for the Cutting frame are listed in Table I.

TABLE I: CORE FrAME ElEMENTS OF THE CUTTING FRAME

\begin{tabular}{ll}
\hline \hline Frame Element & Definition \\
\hline Agent & The person cutting the Item into Pieces \\
Item & $\begin{array}{l}\text { The item which is being cut into Pieces } \\
\text { The parts of the original Item which are the result } \\
\text { Pieces }\end{array}$ \\
\hline \hline
\end{tabular}

The non-core frame elements specified for the cutting frame are shown in Table II.

TABLE II: NON-CORE FRAME ELEMENTS OF THE CUTTING FRAME

\begin{tabular}{ll}
\hline \hline Frame Element & Definition \\
\hline Instrument & $\begin{array}{l}\text { The instrument with which the Item is being cut } \\
\text { into Pieces } \\
\text { Manner }\end{array}$ \\
Means & An act of the Agent that accomplishes the slicing \\
Place & Where the slicing takes place \\
Purpose & The purpose for which the Item is being sliced \\
Result & into Pieces \\
Time & The result of the Item being sliced into Pieces \\
\hline \hline
\end{tabular}

The description of a frame in the FrameNet database contains also the lexical units which evoke the frame. The list of lexical units that evokes the Cutting frame includes carve, chop, cube, cut, dice, fillet, mince, pare, and slice.

FrameNet additionally specifies a network of relations between frames. Table III shows three of them.

TABLE III: THREE FRAME-TO-FRAME RELATIONS

\begin{tabular}{ll}
\hline \hline Relation & Definition \\
\hline Inheritance & $\begin{array}{l}\text { Frame A inherits from frame B, if A is a subtype } \\
\text { of B }\end{array}$ \\
Using & $\begin{array}{l}\text { Frame A uses frame B, if A presupposes B as } \\
\text { background }\end{array}$ \\
Subframe & $\begin{array}{l}\text { Frame A is a subframe of frame B, if B is a } \\
\text { complex frame containing A as a part } \\
\text { Precedes }\end{array}$ \\
& $\begin{array}{l}\text { The precedes relation captures a temporal order } \\
\text { that holds between subframes of a complex } \\
\text { scenario }\end{array}$ \\
\hline \hline
\end{tabular}

The only frame-to-frame relation specified in the FrameNet database for Cutting is that of Inheritance. The specification indicates that Cutting inherits from the frame Intentionally_affect. As for this latter frame, it inherits from 
two other frames, namely Intentionally_act and Transitive_action. FrameNet has developed a visualization tool, FrameGrapher, for viewing the relations between frames and their frame elements. Fig. 1 shows the diagram that FrameGrapher generates in response to a request for viewing the Inheritance relations starting from the Cutting frame.

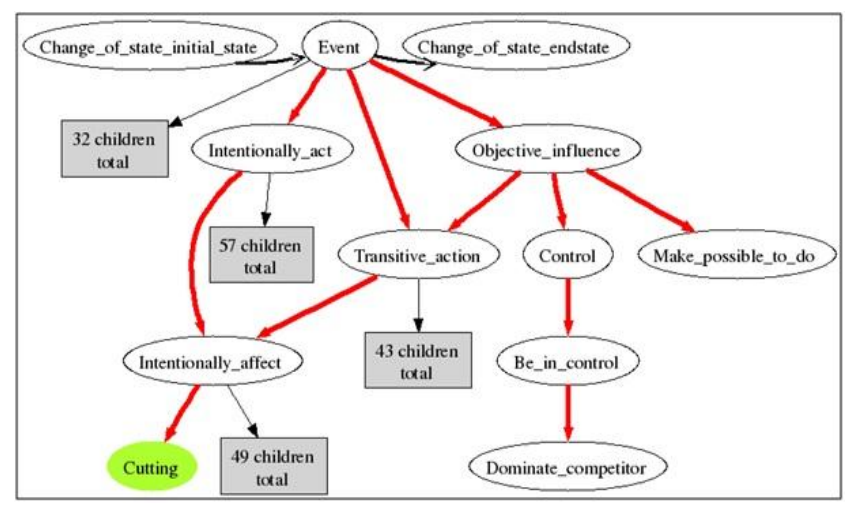

Fig. 1. A fragment of the inheritance relations.

The frame Intentionally_affect is associated with the following definition: An Agent causes a Patient to be affected, sometimes by a particular Means or by use of an Instrument.

Agent and Patient are specified in the FrameNet database as the core frame elements of this frame ${ }^{2}$. Table IV shows the definitions provided for them.

TABLE IV: CORE FRAME ELEMENTS OF THE INTENTIONALLY_AFFECT FRAME

\begin{tabular}{ll}
\hline \hline Frame Element & Definition \\
\hline Agent & $\begin{array}{l}\text { The conscious entity, generally a person that } \\
\text { performs the intentional act that affects the patient } \\
\text { The entity acted on and that may, but need not, } \\
\text { Patient }\end{array}$ \\
\hline \hline
\end{tabular}

There is an important point to note about the Inheritance relation: if a frame inherits from another, a mapping is specified between the frame elements of these two frames. The mapping between the identically named frame elements of the frames Cutting and Intentionally_affect is self-evident (e.g., the mappings between Agents or Instruments). Besides, there is a mapping between an Item of Cutting and a Patient of Intentionally_affect, with an Item being a specific type of Patient.

The Inheritance relation organizes the frames into a hierarchy, a fragment of which is illustrated in Fig. 1. One claim of this paper is that thematic roles, too, can be hierarchically organized and can thereby serve as an interface between FrameNet and the grammar of natural language. We can now move on to the discussion of these abstract semantic roles.

\section{Partitioning Thematic Roles INTO ThreE FIELDS}

Thematic roles are "the grammatically relevant semantic relations between predicates and arguments" ([14], p. 201). They are usually assumed to constitute a finite set. The

\footnotetext{
${ }^{2}$ There is also a frame element named event and categorized as "Core Unexpressed" in the specification of the Intentionally_affect frame.
}

following is one such set that includes some popular roles: \{Location, Source, Goal, Path, Theme, Actor, Patient, Instrument, Experiencer $\}^{3}$.

We share the not uncommon dissatisfaction with the conception of thematic roles as distinct elements of a finite set. We argue that thematic roles must be intrinsically organized in a mathematical structure that is richer than that of a flat set (i.e., a set that contains non-sets as elements). In what follows, we sketch an argument to show that thematic roles are organized as hierarchical structures.

The problem with the flat of thematic roles is that the elements are merely put side by side as if they are discrete and irrelevant to each other. As a quick glance through the definitions in Table $\mathrm{V}$ will reveal, some members of this set share certain interpretive commonalities that make them a group against the others.

TABLE V: SOME DEFINITIONS OF THEMATIC ROLES

\begin{tabular}{ll}
\hline \hline Thematic Role & Definition \\
\hline Location & The place where something is \\
Source & The place from which an entity moves \\
Goal & The place toward which an entity moves \\
Path & The trajectory along which an entity goes from a \\
source to a goal & An entity in motion or being located \\
Actor & The initiator of an action \\
Patient & An entity affected by an action \\
Instrument & An object with which an action is performed \\
Experiencer & An individual that feels, perceives, or cognizes a \\
& situation \\
\hline \hline
\end{tabular}

On the one hand, we have a group of locative roles that might be assigned to places: Location, Source, Goal and Path. On the other hand, we have a group of roles to be assigned to entities that might be located in these places: Theme, Actor, Patient and Instrument. Lastly, we have the role Experiencer that is to be assigned to individuals who feel, perceive or cognize the latter being located in the former. Hence, the set of thematic roles can be divided into three subsets as follows: $\{\{$ Location, Source, Goal, Path $\},\{$ Theme, Actor, Patient, Instrument $\}$, $\{$ Experiencer $\}$.

The following example illustrates each of the roles given in Table V: "In the gloomy house, the man walked from the living room to the kitchen through a narrow hallway. He saw the maid chopping an onion with a knife." The prepositional phrases in the first sentence express the locative roles. The subject of the same sentence illustrates the role Theme. As for the second sentence, the subject of the matrix clause denotes an Experiencer while the subject and object of the subordinate clause and the with phrase illustrate the roles Actor, Patient and Instrument, respectively.

The semantic basis of the tripartition of thematic roles seems to lie in the figure-ground dichotomy of Gestalt psychology. According to a well-known principle of this school of psychology, a human perceiver automatically segregates a scene into a figure and a ground, with the former standing out against the latter. The proposed tripartition can be taken as a rewording of this principle in set notation: the locative and located roles come, respectively, from the

\footnotetext{
${ }^{3}$ Most of the roles in this set were introduced by Jackendoff in [15], and all have come into general use since then.
} 
ground and the figure; and, the Experiencer corresponds to the perceiver that segregates a scene into a figure and a ground. Henceforth, the set of locative roles will be referred to as the locative field, the set of located roles as the figural field and the set associated with the Experiencer as the psychological field.

\section{DE-FLATTENING ThE THEMATIC FIELDS}

We further argue that the tripartite set of thematic roles is still too flat to capture the depth of the structure in which the thematic roles are organized. The thematic fields should be de-flattened for the following reasons.

First, each locative role points to a place that serves as a location at some point of the situation described. For instance, the living room, the kitchen and the hallway are, respectively, the Source, Goal and Path in the situation described by the sentence "In the gloomy house, the man walked from the living room to the kitchen through a narrow hallway." But, note that each of these specifies a place where the man was at a different time interval of the situation. Therefore, we should somehow make their locative character explicit. Besides, a Path can be characterized as a Goal and a Source. For example, the hallway served as the goal to which the man moved at the beginning of the situation and as the source from which he came out at the end. Thus, for the sake of explicitness, we will refer to a Source, a Goal and a Path as a Locative_source, a Locative_goal and a Locative_path, respectively. In addition, a place that serves solely as a Location will be dubbed merely as locative. Fig. 2 is a diagrammatic representation of the is-a (i.e., relations) among the locative roles.

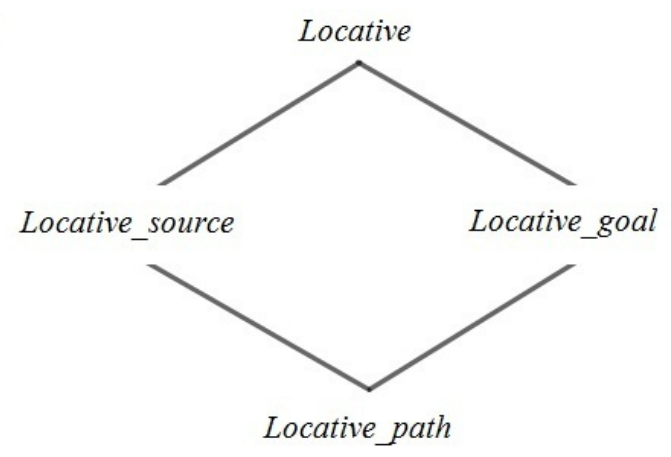

Fig. 2. The is-a relations among the locative roles.

Second, each figural role points to an entity that is located somewhere. A Theme is a located entity by definition. Besides, all Actors and Patients are necessarily located in a place as all actions must take place somewhere. As for the Instrument, since it is used to accomplish the action, it has to be collocated with the Actor and Patient. We propose to capture this common property of the figural roles (i.e., being located in a place) by specifying each of them as Figural. A Theme is merely Figural. An Actor is a Figural_source as it is the source of action. A Patient is a Figural_goal as it is the goal of action. Furthermore, an Instrument can be considered as a Figural_path through which action flows from the Source to the Goal. Therefore, the is-a relations among the figural roles can be described as in Fig. 3 .

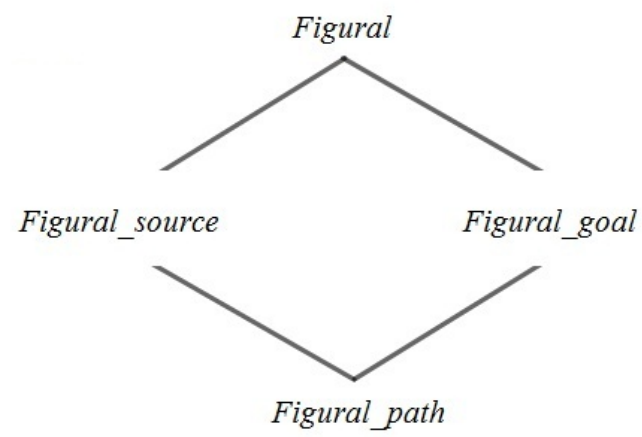

Fig. 3. The is-a relations among the figural roles.

Third, we argue that the psychological field can be given a similar treatment. Gruber [16] considers the complement in a sentence like the following as an 'informational theme' of an 'abstract transition': "John learned that the earth was flat from Bill." We can give a paraphrase of Gruber's example: "The information that the earth was flat 'moved' from a source (Bill's mind) to a goal (John's mind)." In the light of such examples, we propose to add the roles Psychological_source and Psychological_goal to our inventory of thematic roles. A mere experiencer, as the man in a situation described by the sentence "The man saw the maid chopping an onion with a knife," is solely Psychological. However, the experiencers as John and Bill in Gruber's example can be characterized as Psychological_source and Psychological_goal, respectively. We also need the notion of Psychological_path, because the sense organs can be thought of as 'paths' through which information flows (from a situation) to one's mind. The diagram in Fig. 4 represents the hierarchical organization of the psychological field.

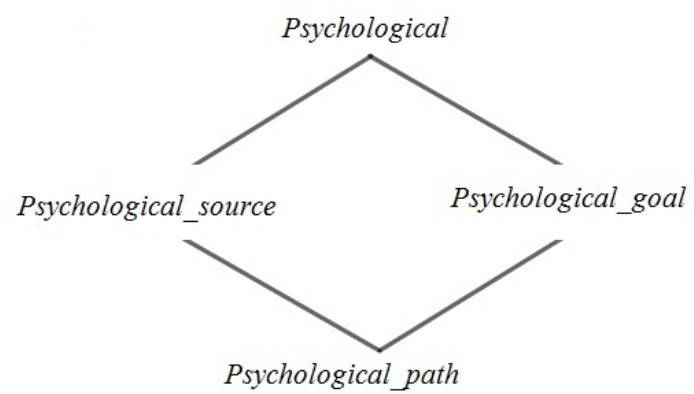

Fig. 4. The hierarchical organization of the psychological field

In fact, (re)organizing the thematic roles among themselves, which is what we have done up to this point, is not the only way to enrich the structures in which they are intrinsically organized. Another way of enriching the thematic role structures is by adding a new parameter to the model, which is what we will do in what follows.

\section{ENRICHING THE THEMATIC ROLE STRUCTURES WITH A REFERENCE PARAMETER}

\section{A. Locative References}

As pointed out by many philosophers including Aristotle, locations (or places) need to be ontologically distinguished from entities [17], [18]. Without delving into the philosophical debate, we shall draw a distinction between 
'mere locations' and 'locative references' which corresponds to the ontological distinction between locations and entities and seems operative in the grammar. There is a certain group of nouns that are used only when referring to (mere) locations: 'inside', 'right', 'here', 'there', 'place', 'area', etc ${ }^{4}$. As for locative references, they are not different from Jackendoff's 'references,' [14] Langacker's 'landmarks' [13] or Talmy's 'Grounds.' [21]. Consider the sentence "The mouse was in the box." The expression "in the box" lexicalizes the location of the mouse, whereas "the box" is the expression denoting the locative reference with respect to which that location is determined. Notice that this sentence can be continued as follows: "It is still in the same place but the box has somehow disappeared from there." That is, the location can be divorced from the encompassing box and be anaphorically referred to by 'there.'

The box in the above example is a reference of location. Similarly, "past me", "from under the table," and "to the right of the vase" in the sentence "The mouse ran past the maid from under the table to the right of the vase" lexicalize reference points: a reference of path, a reference of source, and a reference of goal, respectively.

In order for our model to express reference roles, we add Reference_of_location, Reference_of source, Reference_of _goal and Reference_of path to the set of thematic roles. With these roles, we get to the structure shown in Fig. 5 for the locative field.

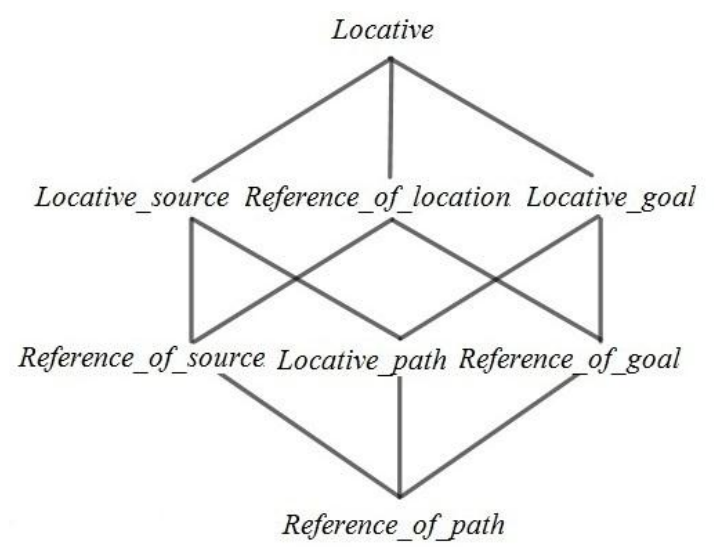

Fig. 5. The structure for the locative field.

We suggest that references pervade all the thematic fields, though differing in their ontological statuses.

\section{B. Figural References}

According to situation theory, a mathematical theory of situations, a situation is a part of the world which a cognitive agent might perceive [22]. As Cooper points out in [23], situations are directly perceived by organisms with a capacity of perception. As for entities, they are abstract objects which codify the result of some kind of cognitive process or perception. More formally, situations are first-order objects of the theory whereas individual entities are objects derived as higher level uniformities across situations. In our words, a situation serves for a perceiver as a reference with respect to

\footnotetext{
${ }^{4}$ Reference [19] characterizes such nouns as 'place-denoting' (as opposed to 'entity-denoting' nouns) and Reference [20] uses the term 'cryptotype' to refer to that kind of nouns.
}

which s/he identifies an entity.

A question may arise now as to whether situational references are really operative in the grammar. Languages provide supporting evidence for a positive answer to this question. An interesting piece of evidence comes from the accusative case morpheme in Turkish. The direct object of a Turkish sentence may or may not carry this morpheme ${ }^{5}$. Kılıçaslan (2006) offers a semantic account of that case-marking alternation in Turkish in terms of the situation-theoretic distinction between described and resource situations. He claims that the semantic content of a non-case-marked object is necessarily part of the described situation, i.e. the situation referred to by the sentence the object occurs in, whereas the semantic content of a case-marked-object is donated by a resource situation, i.e. another situation exploited to describe the situation referred to. In our terms, the lack of case morphology on a direct object in Turkish indicates that the reference with respect to which the object is identified is the described situation and the use of the accusative case morpheme signals that the object is identified with respect to a situation other than the described one (i.e. with respect to a resource situation). Resource situations were introduced by Barwise and Perry (1983) in order to be able to treat definite descriptions. Kilıçaslan in [27] shows that in English not only the reference of definite determiners but the domains of quantification of all strong quantifiers (such as every, each, most etc.) are determined with respect to resource situations not identical with the described situation. We will not go any further into the linguistic encoding of the distinction between resource situations and described ones. What is of direct relevance to the discussion in this section is that situational references always seem to come into play for identifying entities that might function as Themes.

In the light of the observations above we propose to supplement the figural field with a situational reference (Sit_reference). Hence, the model for this field can be augmented as in Fig. 6.

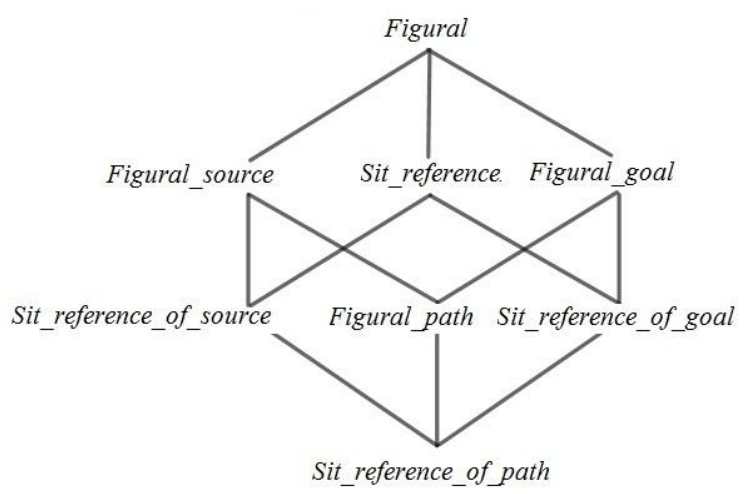

Fig. 6. The model for the figural field.

In short, a situational reference (i.e. a resource situation) is to an entity what an entity is to a location.

\section{Psychological References}

The psychological field can be given a similar treatment so that it can accommodate a reference parameter. Without

\footnotetext{
${ }^{5}$ That is, Turkish is one of the many languages that exhibit so called Differential Object Marking [24]-[26].
} 
going into a detailed argument, we will be content to note that it is not the individual per se but his/her mind that should ultimately be considered as where information resides, moves from or moves to. That is, an individual can be taken as a reference with respect to which his/her mind is referred to. We will refer to such a reference as an individual reference (Ind_reference). Hence, we have the diagram in Fig. 7, showing the structure for the psychological field.

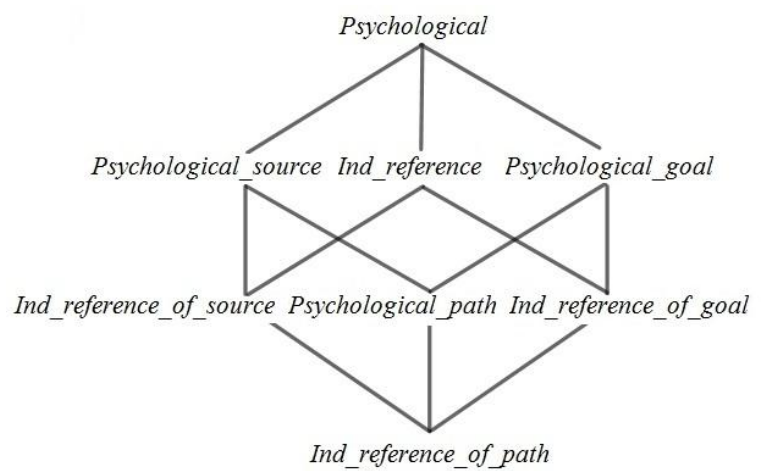

Fig. 7. The model for the psychological field.

In a sense, an individual is to his/her mind what a physical entity is to a location or what a situation is to an entity.

\section{LinKING FRAMENET AND THE THEMATIC ROLE STRUCTURES}

Recall from Section II that a frame is a schematic representation of a situation involving various participants. Hence, a frame can serve as what we have referred to above as the situational reference with respect to which an entity is identified. Furthermore, certain frames can thereby serve as contact points between the FrameNet database and the thematic role structures introduced in the previous section. Once all the thematic structures have been integrated as a single structure, which we plan as future work, all information concerning the semantic roles defined in a frame can flow to the relevant nodes via the node of situational reference. The question to raise at this point is which frames can serve as contact points between the FrameNet database and our thematic role structures. Can, for instance, the two frames introduced in Section II, namely Cutting and Intentionally_affect, serve for this purpose?

Remember that a semantic role has to be grammatically relevant in order to be considered also as a thematic role. The level at which the frame Cutting is defined seems to be too specific for the distinctions made there to be grammatically relevant. For instance, no natural language in the world appears to have rules of grammatical structure dedicated to encode the frame element Item. In other words, no language is grammatically sensitive to the role of being cut into Pieces. Again, the frame element Agent as defined for Cutting, i.e., the person cutting an Item into Pieces, cannot be visible to the grammar of natural language. In short, the grammar of natural language is simply blind to the degree of specificity exhibited by Cutting.

However, the level where the Intentionally_affect frame is defined seems to exhibit a degree of abstraction that allows for grammatical structures to emerge. It is well-known that all languages in the world are grammatically sensitive to the Agent-Patient distinction as defined at this level. More specifically, these are two of the so-called thematic roles. The Patient of Intentionally_affect is, more or less, the same as the Patient defined in Section III. However, the Agent defined in this frame is 'slightly' different from the Actor defined there: it has to be a conscious entity. This Agent role can be captured in our model by defining a new structure that inherits both the figural field and the psychological field. The frame Intentionally_affect can felicitously serve as a situational reference for this inter-field and, thereby, link the thematic role structure to FrameNet. Such inter-fields will come into being once all the thematic structures are integrated into a single structure.

It is noteworthy that if we move upward from the frame Intentionally_affect (cf. Fig. 1), we can reach a level of abstraction where the core elements are nearly the same as the two thematic roles Actor and Patient as defined in Section III. This is the level where the frame Transitive_action is defined: This frame characterizes, at a very abstract level, an Agent or Cause affecting a Patient. Actor and Patient are specified for this frame as in Table VI.

TABLE VI: CORE FRAME ELEMENTS OF THE TRANSITIVE_ACTION FRAME

\begin{tabular}{ll}
\hline \hline Frame Element & Definition \\
\hline Agent & The entity that acts on another entity \\
Patient & $\begin{array}{l}\text { The entity acted on and that may, but need not, } \\
\text { undergo a change }\end{array}$ \\
\hline \hline
\end{tabular}

That is to say, the Transitive_action frame can serve as a situational reference for the figural field and, in this way, link this field to FrameNet.

Another frame that can serve a linking function is Mental_activity: A Sentient entity has some activity of the mind operating on a particular Content or about a particular Topic. The particular activity may be perceptual, emotional, or more generally cognitive. This frame links FrameNet to the psychological field. It corresponds to an individual's mind. The individual serving as a reference for this field is specified as a core element of the Mental_activity frame with the name 'Sentient_entity' (see Table VII).

TABLE VII: A CORE FRAME ELEMENT OF THE MENTAL_ACTIVITY FRAME

\begin{tabular}{ll}
\hline \hline Frame Element & Definition \\
\hline Sentient_entity & $\begin{array}{l}\text { The individual whose mind has a particular piece } \\
\text { of Content in it. } \\
\text { The situation or state-of-affairs that the } \\
\text { Content }\end{array}$ \\
\hline \hline
\end{tabular}

The Content of the Sentient_entity's mind is the situation serving as the reference of the figural field (see Table VII).

It should be noted that the FrameNet lexical database contains around 1200 semantic frames and that each of these frames comes with a number of core and non-core frame semantic roles. Linking these roles to appropriate nodes in a thematic role structure will allow to see the hierarchical relations among them holistically and in a clearer way albeit at an abstract level.

Thematic roles play a central role in the syntax-semantics interface in many syntactic theories. The thematic structures presented in this study can hopefully enhance our 
understanding of how thematic roles interface between the syntax and semantics of natural language. Speaking broadly, it seems that the locative roles tend to be lexicalized as prepositional phrases while the roles in the figural and psychological fields are more likely to be encoded as subjects or direct objects. Therefore, a model can be developed where the constituents of a sentence can be linked to the relevant parts of FrameNet via the mediation of the thematic role structures: the verb to a lexical unit evoking a frame; the name of that frame or the name of a more abstract frame it inherits from to the Sit_reference node of the figural field, the subject or direct objects to the relevant nodes of that field if the verb is non-psychological; the name of the frame to a mind-representing node of the psychological field, with the Sentient_entity being linked to the individual whose mind is described and the Content being linked to the situational reference of the figural field, if the verb is psychological; and, finally, the locative prepositional phrases to the relevant nodes of the locative field.

\section{CONCLUSION}

We have proposed that thematic roles can be organized into hierarchical structures and that these structures can be linked to the FrameNet lexical database and, thereby, serve as a mediator between FrameNet and the syntactic constituents of a natural language. Admittedly, this is only a research-based step toward the goal of linking natural language and FrameNet in a precise way. Given that many attempts have been made to link the FrameNet database to the lexical resources like WordNet and VerbNet and to ontologies like Sumo, a precisely defined model of linking natural languages to FrameNet will offer exciting opportunities and avenues for the fields of natural language processing, computational linguistics, informational retrieval etc., which justifies our research effort.

\section{REFERENCES}

[1] C. J. Fillmore, "Frame semantics and the nature of language," in Origins and Evolution of Language and Speech, vol. 280, S. R. Harnad, H. D. Steklis, and J. Lancaster, Eds. 1976, pp. 20-32.

[2] C. J. Fillmore, "The need for frame semantics within linguistics," Statistical Methods in Linguistics, vol. 12, pp. 5-29, 1976.

[3] C. J. Fillmore, "Scenes-and-frames semantics," in Linguistics Structures Processing, A. Zampolli, Ed. Amsterdam and New York: North Holland Publishing Company, 1977, pp. 55-81.

[4] C. J. Fillmore, "Frame semantics," in Linguistics in the Morning Calm, D. Geeraerts Ed. Seoul: Hanshin Publishing, 1982, pp. 111-137.

[5] C. J. Fillmore, "Frames and the semantics of understanding," Quaderni di Semantica, vol. 6, no. 2, pp. 222-254, 1985.

[6] C. J. Fillmore and B. T. S. Atkins, "Toward a frame-based lexicon: The semantics of RISK and its neighbors," in Frames, Fields, and Contrasts, A. Lehrer and E. F. Kittay, Eds. NJ: Lawrence Erlbaum Associates Hillsdale, 1992, pp. 74-102.

[7] C. J. Fillmore and B. T. S. Atkins, "FrameNet and lexicographic relevance," in Proc. LREC, Granada, Spain, 1998.

[8] C. J. Fillmore and C. F. Baker, "Frame semantics for text understanding," in Proc. WordNet and Other Lexical Resources Workshop, 2001.
[9] C. J. Fillmore and C. F. Baker, "A frames approach to semantic analysis," in the Oxford Handbook of Linguistic Analysis, B. Heine and H. Narrog, Eds. Oxford: Oxford University Press, 2010, pp. 313-340.

[10] C. J. Fillmore, C. R. Johnson, and M. R. L. Petruck, "Background to FrameNet," International Journal of Lexicography, vol. 16, no. 3, pp. 235-250, 2003.

[11] C. J. Fillmore, "Valency and semantic roles: The concept of deep structure case," in Dependency and Valency, V. Ágel, L. M. Eichinger, H. W. Eroms, P. Hellwig, H. J. Heringer, \& H. Lobin, Eds. Berlin: de Gruyter, 2003, vol. 1, pp. 457-475.

[12] R. Langacker, Foundations of Cognitive Grammar, Stanford, CA: Stanford University Press, vol. 1, 1987.

[13] C. J. Fillmore, "Valency issues in FrameNet," in Valency: Theoretical, Descriptive and Cognitive Issues, T. Herbst and K. Gotz-Votteler, Eds. Berlin: Mouton de Gruyter, 2007, pp. 129-160.

[14] W. Frawley, Linguistic Semantics, Hillsdale, NJ: Lawrence Erlbaum Associates, 1992.

[15] R. Jackendoff, Semantic Structures, Cambridge: MIT Press, 1990.

[16] J. Gruber, "Studies in lexical relations," MIT dissertation, 1965.

[17] P. F. Strawson, Individuals, London: Methuen, 1959.

[18] J. L. MacKenzie, "Places and things," in Crucial Readings in Functional Grammar, M. P. Anstey and J. L. MacKenzie, Eds. Berlin and New York: Mouton de Gruyter, 2005, pp. 141-165.

[19] T. Thrane, Referential-Semantic Analysis: Aspects of a Theory of Linguistic Reference, Cambridge: Cambridge University Press, 1980.

[20] B. L. Whorf, "Grammatical categories," Language, vol. 21, no. 1, pp. $1-11,1945$.

[21] L. Talmy, "Semantic structures in English and Atsugewi," Ph.D. dissertation, Department of Linguistics, University of California, Berkeley, 1972.

[22] J. Barwise and J. Perry, Situations and Attitudes, MIT Press, Cambridge, MA, 1983.

[23] R. Cooper, "The role of situations in generalized quantifiers," in Handbook of Contemporary Semantic Theory, S. Lappin, Ed. Blackwell, 1995.

[24] J. Aissen, "Differential object marking: Iconicity vs. economy," Natural Language and Linguistic Theory, vol. 21, pp. 435-483, 2003.

[25] G. Bossong, Empirische Universali Enforschung, Differentielle Objekt Markierung in den Neuiranischensprachen, Narr: Tübingen, 1985.

[26] B. Comrie, "Definite and animate direct objects: A natural class," Lingua, vol. 117, pp. 1636-1656, 1975.

[27] Y. Kiliçaslan, "A situation-theoretic approach to case marking semantics in Turkish," Lingua, vol. 116, no. 2, pp. 112-144, 2006.

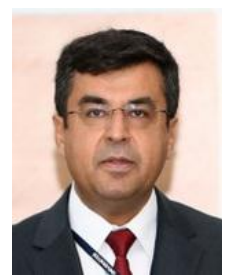

Yılmaz Kılıçaslan is a professor at the Department of Computer Engineering, Faculty of Engineering, Trakya University, Turkey. In 1992, he got his B.Sc. degree in computer science from the Middle East Technical University, Turkey, and then he received his M.Sc. and Ph.D. degrees in cognitive science from the Centre for Cognitive Science and Natural Languages, Division of Informatics, the University of Edinburgh, Scotland, in 1994 and 1998, respectively. His research interests are cognitive linguistics, computational linguistics, natural language processing and machine learning. He has authored papers in refereed journals and international conference proceedings, and has been actively serving as a reviewer for international journals and conferences.

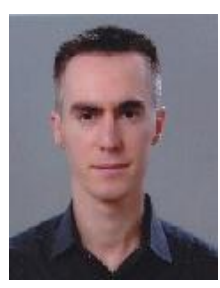

Gurkan Tuna is an associate professor at the Department of Computer Programming of Trakya University, Turkey since 2006. He has authored several papers in international conference proceedings and refereed journals, and has been actively serving as a reviewer for international journals and conferences. His research interests are machine learning, natural language processing, robotics, and wireless sensor networks. 